\title{
Wearing High Heel Shoes during Gait: Kinematics Impact and Determination of Comfort Height
}

\author{
Koussihouèdé Fifamè Eudia Nadège ${ }^{1}$, Falola Jean-Marie ${ }^{1,2,{ }^{*}}$, Lawani Mohamed Mansourou ${ }^{1}$, \\ Gouthon Polycarpe ${ }^{3}$, Avossevou Yves Gabriel ${ }^{4}$, Lawani Sophia ${ }^{1}$ \\ ${ }^{1}$ Laboratory of Biomechanics and Performance (LABIOP), National Institute of Youth, Physical Education and Sport (INJEPS) University of \\ Abomey Calavi (UAC), Porto-Novo, Benin \\ ${ }^{2}$ Laboratory Human Motricity, Education, Sport, Health (LAMHESS) Training Unit and Research in Sciences and Techniques of Physical \\ and Sports Activities (STAPS) University of Nice Sophia Antipolis, Nice, France \\ ${ }^{3}$ Laboratory APS and Motricity (LABAPSM), National Institute of Youth, Physical Education and Sport (INJEPS) University of Abomey \\ (UAC), Porto-Novo Benin \\ ${ }^{4}$ Research Unit Theoretical Physics (URPT) Institute of Mathematics and Physical Sciences (IMSP) University of Abomey Calavi (UAC), \\ Porto-Novo Benin
}

\section{Emailaddress:}

eudiak@yahoo.fr (K. F. E. Nadège),mjfalola@hotmail.com (F. Jean-Marie), jemfalola@yahoo.fr (F. Jean-Marie), bissiriou03@yahoo.fr (L. M. Mansourou), goupoly@yahoo.fr (G. Polycarpe), avossevou@yahoo.fr (A. Y. Gabriel), lawansoak1@yahoo.fr (L. Sophia)

\section{To cite this article:}

Koussihouèdé Fifamè Eudia Nadège, Falola Jean-Marie, Lawani Mohamed Mansourou, Gouthon Polycarpe, Avossevou Yves Gabriel, Lawani Sophia. Wearing High Heel Shoes During Gait: Kinematics Impact and Determination of Comfort Height. American Journal of Life Sciences. Vol. 3, No. 2, 2015, pp. 56-61. doi: 10.11648/j.ajls.20150302.11

\begin{abstract}
Real attribute of femininity, wearing high-heeled shoes is a dress conduct of women in daily and professional tasks. Objectives. Consider the kinematics changes induced by walking heels and determine a height of comfort in the least intrusive possible locomotor pattern. Materials and methods. Fifteen young women had normal-weighted were walked with shoes without heel and with eight-heeled shoes, successive heights ranging from 2 to $9 \mathrm{~cm}$ in freely chosen speed without heel shoes, with three step frequencies: $\pm 20 \% \mathrm{~F}_{\text {fcwh }}$ (frequency step freely chosen to heel without shoes) and $0 \% \mathrm{~F}_{\text {fcwh }}$. Results. The locomotor pattern was more affected by wearing heels at $\pm 20 \%$ of frequency selected freely chosen in shoe without heel than $0 \%$. The height of the comfort of the shoe heel in the step is $4.13 \mathrm{~cm} \pm 0.34$.
\end{abstract}

Keywords: Gait, Kinematics Parameters, High Heels, Comfort Height

\section{Introduction}

Wearing high heels is a dress behavior adopted by 37 to $69 \%$ of women in the world (Frey and al., 1993). This behavior is already widespread in developing countries such as Benin. For this purpose, a pre-survey in the three cities with special status in the country indicates that $95.5 \%$ of women employees wear heels. Wearing high heels, became part of the dress, and was the subject of several studies. In the literature, it is well established that in biped station, wearing high heels affect the posture of the axial skeleton (Koussihouèdé and al., 2014). On the kinetics and joint planes, it increase the risks of developing of patellofemoral and ankle pains (Ko and Lee, 2013; Speksnijder and al., 2005). This increase is due to an abnormal distribution of body weight on the foot (Snow and Williams, 1994) resulting risk of joint osteoarthritis (Barkema and al., 2012 ; Cowley and al., 2009). About the locomotor pattern, the studies of spatiotemporal parameters indicated that the duration of the stance phase, the stride length and step angle were significantly decreased in high heels (Simonsen and al., 2011 ; Snow and Williams, 1994 ; Opila-Correira, 1990). Disturbances above identified have implications for instability and imbalance of the body resulting an increased risk of falling and slipping (Ko and Lee, 2013 ; Ryu, 2010 ; Ebbeling and al., 1994).

However, Benin is a country in sub-Saharan Africa, where wearing high heels has become not only a dress behavior, but 
also a professional requirement because of the occupied workstations. In this context, it is important to determine the height of comfort heel of the shoe to less disruption of the locomotor pattern through a quantitative gait analysis.

\section{Materials and Methods}

\subsection{Type of Study and Implementation Framework}

This is a controlled prospective study, which took part in the Laboratory for Biomechanics and Performance (LABIOP) of the National Youth Institute of Physical Education and Sport (INJEPS)

\subsection{Study Population and Sampling}

The target population consists of women who had worn high-heeled shoes of public and private institutions of PortoNovo, one of the special status cities of Benin. The study was included a non-probability sample of fifteen healthy women with normal overweight $\left(\mathrm{BMI}=22.17 \pm 1.72 \mathrm{~kg} \mathrm{~m}^{-2}\right)$, volunteers, aged $22.4 \pm 2.56$ years and assigned the wearing high-heeled shoes as a professional dress requirement.

\subsection{Materials}

- Measurements of body mass and height were performed using respectively, scales (Seca, electronic, France) extended $150 \mathrm{~kg}$ and $0.1 \mathrm{~kg}$ precision and a fathom (206 Bodymeter Seca, Wall, France), range $2.20 \mathrm{~m}$, accurate to within $1 \mathrm{~mm}$.

- $\quad$ All the kinematic gait parameters were collected with OptoJump Next system (Microgate, version 1.8.10.0, Switzerland) which was connected to a computer where the data were transferred.

- The gait took place on a treadmill at a slope of $+1 \%$ (Tehnogymn, slope $-5^{\circ}$ to $+25^{\circ}$, China) with a pair of shoes without heel and eight pairs of heels (Collection, based wide, Italy) height $2 \mathrm{~cm}, 3 \mathrm{~cm}, 4 \mathrm{~cm}, 5 \mathrm{~cm}, 6 \mathrm{~cm}$, $7 \mathrm{~cm}, 8 \mathrm{~cm}$ and $9 \mathrm{~cm}$. The base of the heels of shoe model used was a square of $5.3 \mathrm{~cm}$.

- $\quad$ The heart rate at rest and walking were measured with a heart rate monitor (Polar RS 800 SD, Electronics, Finland).

- The step rate was imposed by a metronome (Seiko DM20, Digital, Deutschland) for the duration of walking on treadmill.

\subsection{Experimental Protocol}

A phase of addiction laboratory equipment was used to determine the speed gait freely chosen in shoes without heel $\left(\mathrm{S}_{\mathrm{fcwh}}\right)$. On this basis, the step frequency freely chosen in shoes without heel $\left(\mathrm{F}_{\mathrm{fcwh}}\right)$ was also determined. The test consisted of walking on the treadmill at a slope of $+1 \%$, at the $\mathrm{S}_{\mathrm{fcwh}}$ for six minutes. Each heel shoe height was imposed, three step frequencies: $\pm 20 \% \mathrm{~F}_{\text {fcwh }}$ and $0 \% \mathrm{~F}_{\text {fcwh }}$. Walking with shoes without heel was the reference condition. In total, the subjects were walking in twenty five conditions that were all randomized.

\subsection{Variables Measured}

The kinematics parameters of the motion that is the stride length (SL), the duration of the stance phase (DStP), the duration of the swing phase (DSwP) and the gait ratio (GR) were collected.

The only physiological parameter recorded was heart rate.

\subsection{Data Analysis}

The mean and standard deviation were calculated for each variable. Kolmogorov Smirnov and Barthley tests were used to check respectively the normality and the homogeneity of variances before being applied ANOVA repeated measures (factorial ANOVA) which was used to determine generally if or not there is a significant difference between the variables. The post hoc test Fisher's LSD was used to determine specifically at which heights the differences were significant. Polynomial regression of degree 2 was used for determining the comfort height of heel of the shoe. The level of statistical significance was set at $\mathrm{p}<0.05$.

\subsection{Ethical Considerations}

The study protocol was submitted to the Scientific Committee of Sectorial Sports and Physical Activities of Science and Technology of the University of Abomey-Calavi. Approval to conduct the study was obtained before data collection. Each subject signed a card written informed consent before participating in the study.

\section{Results}

The characteristics of the subjects (Table 1) of this study showed that it was a young population with an average age of 22.40 years \pm 2.56 . They showed, considering the body mass index $\left(\mathrm{BMI}=22.17 \mathrm{~kg} \mathrm{~m}^{-2} \pm 1.72\right)$ that the study sample consists of normal-weighted women.

The comparison of kinematics parameters in shoes without heel $(\mathrm{CWH}=0 \mathrm{~cm})$ and heel shoes $(2 \mathrm{~cm}, 3 \mathrm{~cm}, 4 \mathrm{~cm}, 5 \mathrm{~cm}$, $6 \mathrm{~cm}, 7 \mathrm{~cm}, 8 \mathrm{~cm}$ and $9 \mathrm{~cm}$ ) revealed that $\pm 20 \% \mathrm{~F}_{\text {fcwh }}$, they had presented more significant differences $(\mathrm{p}<0.05)$ than $0 \%$ $\mathrm{F}_{\text {fcwh }}$ (Table 2). Whatever the step frequency $\left( \pm 20 \% \mathrm{~F}_{\text {fcwh }}\right.$ and $\left.0 \% \mathrm{~F}_{\text {fcwh }}\right)$, significant differences were more pronounced with the increase of the height of the shoe heel. These differences were observed from $2 \mathrm{~cm}$ of heel height for the gait ratio at $\pm 20 \% \mathrm{~F}_{\text {fcwh }}$ while at $0 \% \mathrm{~F}_{\text {fcwh }}$, disturbance of locomotor pattern were significant at $5 \mathrm{~cm}$.

The results of the polynomial regression (Figure) showed a significant difference $(\mathrm{p}=0)$ between the comfort height at $20 \% \mathrm{~F}_{\text {fcwh }}(2.5 \mathrm{~cm} \pm 0.79)$ and $0 \% \mathrm{~F}_{\text {fcwh }}(4.13 \mathrm{~cm} \pm 0.34)$. It is the same $(\mathrm{p}<0.01)$ between the comfort height at $0 \% \mathrm{~F}_{\text {fcwh }}$ and $+20 \% \mathrm{~F}_{\text {fcwh }}(3.38 \mathrm{~cm} \pm 0.95)$. The comfort height at a step frequency freely chosen without heel $(4.13 \mathrm{~cm} \pm 0.34)$ was significantly higher than those observed at $\pm 20 \% \mathrm{~F}_{\text {fcwh }}$. The relationship between the heart rate and the step frequencies was indicated that at $\pm 20 \% \mathrm{~F}_{\text {fcwh }}$ the heart rate is 
higher than that at $0 \% \mathrm{~F}_{\text {fcwh. }}$. The final result which emerges is that the comfort height at a step frequency freely chosen without heel is corresponded to the small heart rate. The comfort height which optimizes cardiac function and less disruptive the locomotor pattern is $4.13 \mathrm{~cm} \pm 0.34$.
Table 1. Biometrics subject characteristics.

\begin{tabular}{ll}
\hline & Mean \pm standard deviation \\
\cline { 2 - 2 } & Sample size $=\mathbf{1 5}$ \\
\hline Age (years) & $22,40 \pm 2,56$ \\
Height $(\mathrm{m})$ & $1,63 \pm 0,04$ \\
Body weight $(\mathrm{kg})$ & $59,07 \pm 5,15$ \\
Body mass index $\left(\mathrm{kg} / \mathrm{m}^{2}\right)$ & $22,17 \pm 1,72$ \\
walking speed $(\mathrm{km} / \mathrm{h})$ & $2,63 \pm 0,17$ \\
Width of the heel of the foot $(\mathrm{cm})$ & $5,33 \pm 0,26$ \\
\hline
\end{tabular}

Table 2. Change in kinematics gait parameters at different steps frequencies.

\begin{tabular}{|c|c|c|c|c|c|c|}
\hline & \multicolumn{3}{|c|}{ Stride length $(\mathrm{cm})$} & \multicolumn{3}{|c|}{ Duration of the stance phase (s) } \\
\hline SWH (0 cm) & $-20 \% \mathrm{Fp}_{\text {lcst }}$ & $\begin{array}{l}0 \% \mathrm{Fp}_{\text {lcst }} \\
54,67 \pm 11,14\end{array}$ & $+20 \% \mathrm{Fp}_{\text {lcst }}$ & $-20 \% \mathrm{Fp}_{\text {lcst }}$ & $\begin{array}{l}0 \% \mathrm{Fp}_{\text {lsst }} \\
0,67 \pm 0,28\end{array}$ & $+20 \% \mathrm{Fp}_{\text {lcst }}$ \\
\hline $\mathrm{H} 1(2 \mathrm{~cm})$ & $53,17 \pm 15,67$ & $52,07 \pm 5,34$ & $50,87 \pm 5,11$ & $0,64 \pm 0,33$ & $0,72 \pm 0,12$ & $0,61 \pm 0,50$ \\
\hline $\mathrm{H} 2(3 \mathrm{~cm})$ & $58,93 \pm 5,28$ & $51,67 \pm 6,49$ & $47,87 \pm 13,61$ & $0,65 \pm 0,28$ & $0,68 \pm 0,14$ & $0,61 \pm 0,26$ \\
\hline $\mathrm{H} 3(4 \mathrm{~cm})$ & $59,4 \pm 5,38$ & $51,33 \pm 5,78$ & $47,6 \pm 16,52$ & $0,65 \pm 0,29$ & $0,65 \pm 0,22$ & $0,61 \pm 0,23$ \\
\hline $\mathrm{H} 4(5 \mathrm{~cm})$ & $59,73 \pm 6,3$ & $51 \pm 5,74$ & $47,27 \pm 10,89$ & $0,66 \pm 0,32$ & $0,63 \pm 0,23$ & $0,59 \pm 0,22$ \\
\hline $\mathrm{H} 5(6 \mathrm{~cm})$ & $60,2 \pm 8,55$ & $50,27 \pm 6,20$ & $47,27 \pm 14,82$ & $0,68 \pm 0,32$ & $0,62 \pm 0,23$ & $0,59 \pm 0,22$ \\
\hline $\mathrm{H} 7(8 \mathrm{~cm})$ & $61 \pm 4,3 *$ & $50,07 \pm 6,47$ & $46,00 \pm 8,30 *$ & $0,71 \pm 0,29$ & $0,59 \pm 0,23$ & $0,47 \pm 0,48$ \\
\hline $\mathrm{H} 8(9 \mathrm{~cm})$ & $61,47 \pm 5,62 *$ & $46,13 \pm 8,54 *$ & $43,20 \pm 4,90 * *$ & $0,84 \pm 0,65$ & $0,55 \pm 0,19$ & $0,44 \pm 0,17 *$ \\
\hline
\end{tabular}

Table 2. (Continue).

\begin{tabular}{|c|c|c|c|c|c|c|}
\hline & \multicolumn{3}{|c|}{ Duration of the swing phase (s) } & \multicolumn{3}{|c|}{ Gait ratio (m/step/min) } \\
\hline $\mathrm{SWH}(0 \mathrm{~cm})$ & $-20 \% \mathrm{Fp}_{\text {lcst }}$ & $\begin{array}{l}0 \% \mathrm{Fp}_{\text {lcst }} \\
0,48 \pm 0,13\end{array}$ & $+20 \% \mathrm{Fp}_{\text {lcst }}$ & $-20 \% \mathrm{Fp}_{\text {lcst }}$ & $\begin{array}{l}0 \% \mathrm{Fp}_{\text {lcst }} \\
0,0058 \pm 0,0012\end{array}$ & $+20 \% \mathrm{Fp}_{\text {lcst }}$ \\
\hline $\mathrm{H} 1(2 \mathrm{~cm})$ & $0,67 \pm 0,13 * * *$ & $0,50 \pm 0,17$ & $0,49 \pm 0,05$ & $0,0071 \pm 0,0022 *$ & $0,0054 \pm 0,001$ & $0,0043 \pm 0,0011^{* *}$ \\
\hline $\mathrm{H} 2(3 \mathrm{~cm})$ & $0,71 \pm 0,10 * * *$ & $0,53 \pm 0,08$ & $0,50 \pm 0,17$ & $0,0079 \pm 0,0012 * * *$ & $0,0055 \pm 0,001$ & $0,0043 \pm 0,0014 * *$ \\
\hline $\mathrm{H} 3(4 \mathrm{~cm})$ & $0,72 \pm 0,11 * * *$ & $0,54 \pm 0,11$ & $0,53 \pm 0,12$ & $0,0079 \pm 0,0011 * * *$ & $0,0054 \pm 0,001$ & $0,0042 \pm 0,0015 * * *$ \\
\hline $\mathrm{H} 4(5 \mathrm{~cm})$ & $0,72 \pm 0,07 * * *$ & $0,54 \pm 0,15$ & $0,54 \pm 0,17$ & $0,008 \pm 0,0012 * * *$ & $0,0055 \pm 0,001$ & $0,0042 \pm 0,0012 * * *$ \\
\hline $\mathrm{H} 5(6 \mathrm{~cm})$ & $0,72 \pm 0,07 * * *$ & $0,58 \pm 0,09 *$ & $0,59 \pm 0,06^{*}$ & $0,0081 \pm 0,0012 * * *$ & $0,0055 \pm 0,0008$ & $0,0042 \pm 0,0011 * * *$ \\
\hline $\mathrm{H} 7(8 \mathrm{~cm})$ & $0,73 \pm 0,07 * * *$ & $0,60 \pm 0,08 *$ & $0,60 \pm 0,11 *$ & $0,0081 \pm 0,0009 * * *$ & $0,0054 \pm 0,0008$ & $0,0041 \pm 0,0009 * * *$ \\
\hline $\mathrm{H} 8(9 \mathrm{~cm})$ & $0,73 \pm 0,05 * * *$ & $0,61 \pm 0,10^{* *}$ & $0,61 \pm 0,06 * *$ & $0,0082 \pm 0,0014 * * *$ & $0,0054 \pm 0,0008$ & $0,0038 \pm 0,0006 * * *$ \\
\hline
\end{tabular}

The numbers in the table represent the mean values \pm standard deviation of kinematics parameters; SL: step length; DStP: duration of the stance phase; DSwP: duration of the swing phase; GR: gait ratio; *: Significant difference at $\mathrm{p}<0.05$; $* *$ : Significant difference at $\mathrm{p}<0.01$; $* *$ : Significant difference at $\mathrm{p}<0.001$.

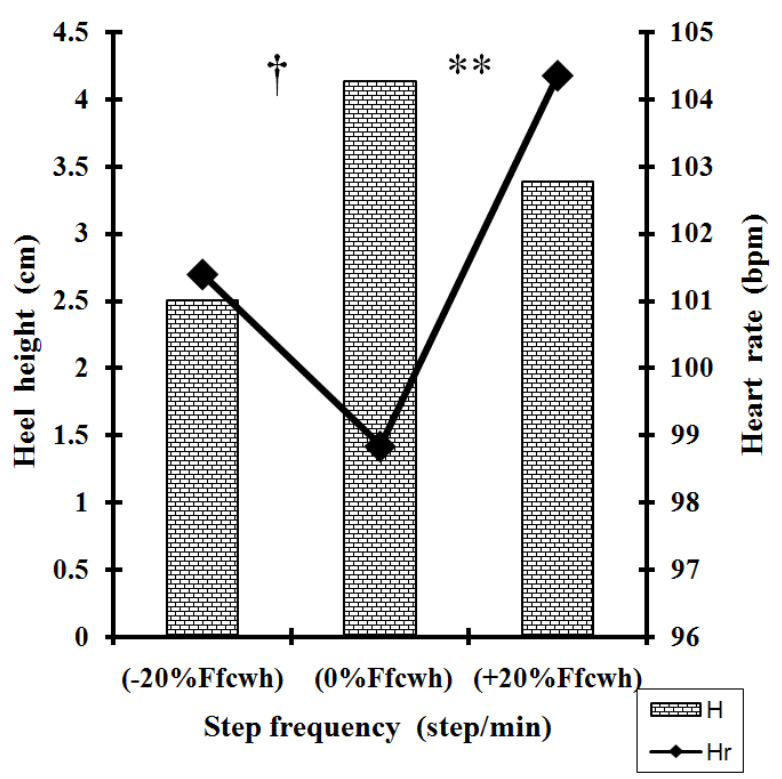

$\dagger$ : Significant difference at $\mathrm{p}=0 ; * *$ : Significant difference at $\mathrm{p}<0.01$;

$\mathrm{F}_{\mathrm{fcwh}}$ : Step frequency freely chosen in shoes without heel

Figure 1. Change comfortable heel height of the shoe according to the step frequency. 


\section{Discussion}

During the course of the study, various dispositions have been taken to ensure the quality and reliability of the data collected. These provisions concern in particular the reduction of systematic error, by the use of the same people for taking measurements in all subjects and the relative error associated with measurement accuracy through the use of the average three successive measurements for each anthropometric variable. Strict compliance with the requirements of device manufacturers also contributed to a better quality of results that seem therefore quite reproducible. This is justified by the nature of high precision devices used for collecting kinematic data. The study was conducted with a sample selected according to non-probability method was chosen in the population of women with high-heeled shoes in the city of Porto-Novo, Benin. In the literature, it is proved that in normal walking, the stance phase occupies $60 \%$ of the cycle and the swing phase $40 \%$ (Viel, 2000; Vaughan and al., 1992) with an invariant gait ratio which is $0.0064 \mathrm{~m} / \mathrm{steps} /$ min for women (Sekiya and al., 1997). The locomotor pattern of the study sample was normal in shoe without heel, because there was no significant difference between the literature values and those observed in subjects. This allows us to deduce that the locomotor pattern in shoes without heel would be similar to that seen walking barefoot. Also Lord and Basford (1996) showed that postural stability during walking in high heel shoes is improved with increasing base of the heel. This has been observed in this study, since for all the shoes, the base of the heel was a square whose side is equal to the width of the heel of the foot of the subject.

In this study, a precise monitoring of the evolution of shoes heels height was used. Shoes heels heights were successive and ranged from $2 \mathrm{~cm}$ to $9 \mathrm{~cm}$. The gait speed and step frequency which were imposed corresponded to those freely chosen in shoes without heel of each subject. They represent those for which the best fuel efficiency is recorded (Vézérian and al., 2001).

The comparison of kinematics parameters of gait with and without heels at $-20 \% \mathrm{~F}_{\mathrm{fcwh}}$ showed a significant increase in SL, DSwP, GR. This increase has pronounced with the increase of the height of the heel of the shoe. All other measured kinematics parameters have shown no significant difference. The significant increase obtained was due to the step frequency that was diminished, which would require about keeping the leg in suspension during the swing phase before laying on the ground at the end of the propulsive phase. While the disturbances pronounced of the kinematics parameters could be justified by the increase of the height of the heel (Cowley and al., 2009).

The observation of kinematics gait parameters with and without heels at $0 \% \mathrm{~F}_{\text {fcwh }}$ showed a significant decrease in SL. These results are in the same direction as those in the literature (Kerrigan and al., 2005; Opila-Correira, 1990) which showed that the stride length in high heels declined. This can be understood through the search for stability and postural balance during walking in high heels. As against a significant increase in DSwP was found. This result mirror those of the literature indicates that increasing the duration of the swing phase due to the height of the heel of the shoe.

As regards the kinematics parameters of the motion to $+20 \%$ $\mathrm{F}_{\text {fcwh }}$, a significant increase of DSwP followed by a significant decrease of SL, DStP and GR are recorded. Observed changes have increased with accentuate of the height of the heel of the shoe. These results confirm those in the literature (Esenyel and al., 2003; Vink and Huson, 1987) that reported a significant decrease in stride length, the cycle length and the duration of the stance phase in heels followed by an increase of the duration of the swing phase.

The results on the evolution of kinematics parameters show that whatever the step frequencies, the locomotor pattern in high-heeled shoes is different from that observed in shoes without heel.

While, it is found that there is more kinematics parameters assigned to $\pm 20 \% \quad F_{\text {fcwh }}$ than at $0 \% \quad F_{\text {fcwh }}$. Increased disturbances at $\pm 20 \% \mathrm{~F}_{\text {fcwh }}$ could be justified by the double constraint imposed on the subjects. These two constraints affect the taxation of the step frequency and walking speed in high heels. What has already been explained by Beauchet and Berrut (2006) who hypothesized that in the case of the double bind, the changes would be obtained due to the interference of the two tasks. This allowed Beauchet and al. (2005), in assessing the effect of a dual task on spatial and temporal parameters, to conclude that the dual task causes significant changes in walking.

Moreover, the reduction of disturbances to the kinematics parameters at $0 \% \mathrm{~F}_{\text {fcwh }}$ can be compared to results of Zarrugh and al. (1978) who have shown that during gait, the step frequency freely chosen induces a lower energy cost and, upstream and downstream thereof, the energy cost is high. This seems justified since the step frequency freely chosen in shoes without heel is that to which the subject feels comfortable in his locomotor pattern. More upstream and downstream $( \pm 20 \%)$ of this step frequency $\left(\mathrm{F}_{\text {fcwh }}\right)$ kinematics disturbances increased.

Polynomial regression of degree 2 found that in walking, there is for each step frequency imposed, a comfort height of the heel of the shoe. When comparing comfort heights obtained at the different steps frequencies, a significant increase is observed between $\pm 20 \% \mathrm{~F}_{\text {fcwh }}$ and $0 \% \mathrm{~F}_{\text {fcwh }}$. This result would mean that $\mathrm{F}_{\text {fcwh }}$ is the one the most comfortable locomotor pattern is observed. What has been explained by Zatsiorsky and al. (1994) who reported that when the subject walking at a speed, he chose a particular combination of stride length and step frequency. This combination represents the best possible condition of the body in walking. Also the height of comfort with $\mathrm{F}_{\text {fcwh }}(4.13 \mathrm{~cm} \pm 0.34)$ is similar to that obtained in the kinetics and electromyographics studies. Indeed, Ryu (2010) suggested that the best heel height to maintain postural balance is between 3 and $5 \mathrm{~cm}$. Ko and Lee (2013) confirm this hypothesis and will conclude that an average of $4 \mathrm{~cm}$ heel is more appropriate for women. 
As regards the heart rate, it was found that each step frequency corresponded a heart rate that is as low as possible. Heart rate obtained at $-20 \% \mathrm{~F}_{\text {fcwh }}$ is $101 \mathrm{bpm} \pm 10.4$. This value of heart rate will decrease at $0 \% \mathrm{~F}_{\text {fcwh }}$ and will be 99 $\mathrm{bpm} \pm 10.15$ before increasing at $+20 \% \mathrm{~F}_{\mathrm{fcwh}}$ to be $104 \mathrm{bpm}$ \pm 9.48 . In other words, the heart rate obtained at $\pm 20 \% \mathrm{~F}_{\text {fcwh }}$ is greater than that observed at $0 \% \mathrm{~F}_{\text {fcwh }}$. This seems justified since $0 \% \mathrm{~F}_{\text {fcwh }}$ is the step frequency that the subject feels comfortable. These results confirm those in the literature (Menant and al., 2008; Falola and al., 1999;. Brisswalter and al, 1996) which indicated that when the subject is free to choose his walking speed, the locomotor pattern corresponds to a step frequency for which the expenditure of metabolic and mechanical energy are minimal.

Furthermore, this result is compatible with that of Zarrugh and al. (1974) who have shown the importance of the inclusion of the step frequency in the general relationship defining the energy cost of walking. To do this, they indicated that the step frequency freely chosen requires less energy regardless of the walking speed. To this end, Mathews and Wooten (1963) indicated that the oxygen consumption increases when walking in high heels. This explains well the increase in heart rate in heeled shoes for our subjects at $\pm 20 \%$ $\mathrm{F}_{\text {fcwh. }}$. This was justified by Holt and al. (1991) who have shown that during freely gait, the preferably step frequency is associated with a minimization of the metabolic cost. The combination of the results to different levels of step frequency conclude that optimizing the gait in terms of energy efficiency and temporal attentional demand is established only by walking speed freely chosen to what is associated a step frequency freely chosen (Sekiya and al., 1997).

\section{Conclusion}

The results of this study show that the disturbances of locomotor pattern are strongly correlated with the increase in the height of the shoe heel. Walking in heels height of 4.13 $\mathrm{cm} \pm 0.34$ at a step frequency freely chosen interferes less locomotor pattern with optimization of heart rate in women. Women carrying heels should not exceed $4.13 \pm 0.34 \mathrm{~cm}$ height at risk of having a locomotor pattern disturbed and to be subject to musculoskeletal disorders.

\section{Acknowledgements}

Acknowledgements to the Scientific Council of the University of Abomey which funded the TEAM POSPROFES for the realization of this study in the context of Interdisciplinary Research Projects and Inter Faculty of Competitive Grant Program for Research of the University of Abomey-Calavi ( $2^{\text {nd }}$ phase).

\section{Conflict of Interests}

The study received partial funding from the University of Abomey-Calavi.

\section{References}

[1] Barkema DD, Derrick TR, Martin PE. Heel height affects lower extremity frontal plane joint moments during walking. Gait Posture. 2012;35(3):483-8.

[2] Beauchet O, Berrut G. Marche et double tâche : définition, intérêts et perspectives chez le sujet âgé. Psychol Neuropsychiatr Vieil. 2006;4(3):215-25.

[3] Beauchet O, Dubost V, Herrmann FR, Kressig RW. Stride-tostride variability while backward counting among healthy young adults. J Neuroengineering Rehabil. 2005;2(26):1-8.

[4] Brisswalter J, Legros P, Durand M. Running economy, preferred step lenght correlated to body dimensions in elite middle distance runners. J Sports Med Phys Fitness. 1996;36:1-9.

[5] Cowley EE, Chevalier TL, Chockalingam N. The effect of heel height on gait and posture. J Am Med Assoc Podiatr. 2009; 99(6):512-8

[6] Ebbeling CJ, Hamill J, Crussemeyer JA. Lower extremity mechanics and energy cost of walking in high-heeled shoes. J Orthop Sports Phys Ther. 1994;19(4):190-6.

[7] Esenyel M, Walsh K, Walden JG, Gitter A. Kinetics of highheeled gait. J Am Podiatr Med Assoc. 2003;30(1):914-8.

[8] Falola JM, Brisswalter J, Delpech N. Effet du port de charge sur le tronc sur la détermination d'une vitesse de marche optimale. Sciences et Motricité. 1999 ;14:201-4.

[9] Frey C, Thompson F, Smith J, Sanders M, Horstman H. American orthopaedic foot and ankle society women's shoe survey. Foot Ankle. 1993;14(2):78-81.

[10] Holt KG, Hamill J, Andres RO. Predicting the minimal energy costs of human walking. Med Sci Sport Exer. 1991;4(23):4918.

[11] Kerrigan DC, Johansson JL, Bryant MG, Boxer JA, Croce UD, Riley PO. Moderate-heeled shoes and knee joint torques relevant to the development and progression of knee osteoarthritis. Arch Phys Med Rehab. 2005;86(5):871-5.

[12] Ko DY, Lee HS. The Changes of COP and foot pressure after one hour's walking wearing high-heeled and flat shoes. J Phys Ther Sci. 2013;25(10):1309-12.

[13] Koussihouèdé FEN, Falola J-M, Falola SMD, Fiogbé MA, Dansou HP. Effet du port de chaussures à talons hauts sur la posture du squelette axial. Cames Santé. 2014 ;2(1) :52-6

[14] Lord SR, Bashford GM. Shoe characteristics and balance in older women. J Am Geriatr Soc. 1996;44:429-33

[15] Mathews DK, Wooten EP. Analysis of oxygen consumption of women while walking in different styles of shoes. Arch Phys Med Rehab. 1963;44:569-71.

[16] Menant JC, Perry SD, Steele JR, Menz HB, Munro BJ, Lord SR. Effects of shoe characteristics on dynamic stability when walking on even and uneven surfaces in young and older people. Arch Phys Med Rehab. 2008;89(10):1970-6.

[17] Opila-Correia KA. Kinematics of high-heeled gait. Arch Phys Med Rehab. 1990;71(5):304-9. 
[18] Ryu JS: Effects of high-heeled shoe with different height on the balance during Standing and walking. KSSB. 2010;20:479-86

[19] Sekiya N, Nagasaki H, Ito H, Furuna T. Optimal walking in terms of variability in stride length. J Orthop Sports Phys Ther. 1997;26(5):266-72.

[20] Simonsen EB, Svendsen MB, Norreslet A, Baldvinsson HK, Heilskov-Hansen T, Larsen PK, Alkjaer T, Henriksen M. Walking on high heels changes muscle activity and the dynamics of human walking significantly. J Appl Biomech. 2012;28(1):20-8.

[21] Snow RE, Williams KR. High heeled shoes: their effect on center of mass position, posture, three-dimensional kinematics, rearfoot motion, and ground reaction forces. Arch Phys Med Rehab. 1994;75(5):568-76.

[22] Speksnijder CM, vd Munckhof RJH, Sjors AFCM. The higher the heel the higher the forefoot-pressure in ten healthy women. Foot. 2005;15:17-21.

[23] Vaughan CL, Davis BL, O'connor JC. Gait analysis laboratory. Champaign IL. Human kinetics Publishers. 1992;1-14.
[24] Vezirian T, Voisin Ph, Dupont B, Chevutschi A, Leleu B. Calcul de l'indice du coût physiologique au cours d'une épreuve de marche. Am Kinésithér. 2001;28(4)162-5.

[25] Viel E. La marche humaine, la course et le saut: biomécanique, explorations, normes et dysfonctionnements. Le Point en rééducation et en APS, 9. Paris : Masson ; 2009. ;267 p

[26] Vink P, Huson A. Lumbar back muscle activity during walking with a leg inequality. Acta Morphol Neer Sc. 1987;25(4):26171 .

[27] Zarrugh MY, Radcliffe CW. Predicting metabolic cost of level walking. Eur J Appl Physiol. 1978;38:215-23.

[28] Zarrugh MY, Todd FN, Ralston HJ. Optimization of energy expenditure during level walking. Eur J Appl Physiol. 1974;33:293-306.

[29] Zatsiorsky VM, Werner SL, Kaimin MA. Basic Kinematics of Walking. Stride length and step Frequency. A review. J Sports Med Phys Fitness. 1994;34:109-34. 